JGG 2021;69:68-78

doi: 10.36150/2499-6564-437

\title{
Thromboembolic disease: a geriatric syndrome
}

\author{
Flavia Galdi, Claudio Pedone, Raffaele Antonelli Incalzi
}

Geriatric Area, Università Campus Bio-Medico, Rome, Italy

The incidence of thrombotic cardiovascular disease increases with age. Several potential reasons can explain the association between thrombosis risk and age, such as the high prevalence of predisposing illnesses among older people and age-related changes in hemostasis pathways, including endothelial dysfunction, alterations in platelet function, coagulation and fibrinolytic factors, that contribute to create a hypercoagulability of the blood. Furthermore, some components of this procoagulant status may also support the inflammatory processes that characterize advancing age, promoting an increased risk of a thrombo-inflammatory disease. However, despite the increased thrombotic risk make the older patient a theoretical target for anticoagulant therapy, the concomitant risk of major bleeding make the use of this drugs problematic, with consequent underuse.

This review summarizes the physiological changes of hemostasis pathways in older people in the context of thromboembolic disease as a geriatric syndrome. The balance between thrombotic and hemorrhagic risk and therefore the therapeutic efficacy of anticoagulant medications are also discussed.

Received: February 20, 2020

Accepted: April 27, 2020

\section{Correspondence}

Flavia Galdi

Geriatric Area, Università Campus Bio-Medico di Roma, via Alvaro del Portillo 21

00128 Rome, Italy. Tel.: +3906225411350.

Fax: +3906 22541456 .

E-mail: f.galdi@unicampus.it

\section{Conflict of interest}

The Authors declare no conflict of interest

How to cite this article: Galdi F, Pedone C, Antonelli Incalzi R. Thromboembolic disease: a geriatric syndrome. Journal of Gerontology and Geriatrics 2021;69:68-78. https://doi.org/10.36150/2499-6564-437

(C) Copyright by Società Italiana di Gerontologia e Geriatria (SIGG)

\section{(c) (1) (3) $\odot$}

\section{OPEN ACCESS}

This is an open access article distributed in accordance with the CC-BY-NC-ND (Creative Commons Attribution-NonCommercial-NoDerivatives 4.0 International) license. The article can be used by giving appropriate credit and mentioning the license, but only for non-commercial purposes and only in the original version. For further information: https://creativecommons.org/licenses/by-nc-nd/4.0/deed.en
Key words: thrombosis, aging, inflammaging, hypercoagulability, thromboprophylaxis

\section{EPIDEMIOLOGY}

The incidence of thrombotic cardiovascular disease (including ischemic heart disease, peripheral vascular disease, stroke and venous thromboembolism [VTE]) increases with age ${ }^{1}$. The average age at first myocardial infarction is 65.6 years for males and 72.0 years for females ${ }^{2}$, and coronary artery disease (CAD) is the principal cause of death in adults aged 75 and older, with more than $80 \%$ of all CAD-related deaths occurring in this population ${ }^{3}$. In addition, approximately $50 \%$ of all strokes occurring in people over age $75^{4}$. The incidence of a first VTE episode, including deep vein thrombosis and pulmonary embolism, increases from $<1$ case per 1000 person-years in persons aged < 50 years to 6-8 per 1000 person-years in persons aged $>80$ years ${ }^{5}$ and data on mortality are limited. In particular, pulmonary embolism (PE) represents an increasing proportion of the manifestations of VTE, with an incidence that increases from 120 in 100,000 persons per year in the 65 to 69 years age group to more than 700 in 100,000 subjects per year in the 85 years and older group ${ }^{6}$. The prognosis of the VTE is very poor in older patients with an overall 30-day mortality that increases from $4 \%$ in patients aged $<65$ years to $11 \%$ in patients aged $\geq 65$ years and remains higher after one year (14\% vs 31\% ${ }^{7}$. In the first 3 months following VTE, the most common causes of death in older subjects are cancer (38\%), 
pulmonary embolism (26\%), infections (13\%) and bleeding complications $(6 \%)^{8}$.

There are several potential explanations for this association between thrombosis risk and age, first of all the common occurrence of predisposing illnesses among older people. Moreover, the risk factors for arterial and venous thromboembolism are more prevalent in older subjects ${ }^{9}$ and they can be distinguished in modifiable and/or temporary risk factors and non-modifiable risk factors ${ }^{10}$ (Tab. I). In addition to the increased level of several plasma components, age-related endothelial dysfunction and alterations in platelet function may contribute to the increased risk of VTE in the elderly ${ }^{9}$.

The aim of this review is to summarize the physiological changes of hemostasis pathways in older people in the context of thromboembolic disease as a geriatric syndrome. In the light of these data, the balance between thrombotic and hemorrhagic risk and therefore the therapeutic efficacy of antithrombotic medications are also discussed.

\section{HEMOSTASIS PATHWAYS AND AGING}

There are two main components of hemostasis: primary hemostasis, that refers to platelet aggregation and platelet plug formation, and secondary hemostasis, that refers to the deposition of insoluble fibrin, which is generated by the proteolytic coagulation cascade. These two processes happen simultaneously and are mechanistically intertwined.

Platelets are activated in a multifaceted process, and as a result they adhere to the site of injury and to each other, promoting a developing platelet thrombus. This platelet plug is also stabilized by deposition of insoluble fibrin generated by the coagulation cascade.

When the vascular system is injured tissue factor (TF), a transmembrane glycoprotein, functions as the principal

Table I. Arterial and venous thromboembolism risk factors.

\begin{tabular}{|l|c|}
\hline $\begin{array}{l}\text { Modifiable and/or } \\
\text { temporary risk factors }\end{array}$ & Non-modifiable risk factors \\
\hline Obesity & $\begin{array}{r}\text { Age } \\
\text { Elenetic factors such as a deficiency } \\
\text { (antithrombin, protein C and S) }\end{array}$ \\
\hline Hospitalization & $\begin{array}{r}\text { Increased concentration of procoagulant } \\
\text { proteins (fibrinogen, factors V, VII, VIII, IX, } \\
\text { XII, D-dimer, VWF, thrombin) }\end{array}$ \\
\hline Cancer & $\begin{array}{l}\text { Surgery } \\
\text { Trauma }\end{array}$ \\
\hline Immobilization & \\
\hline Travel & \\
\hline
\end{tabular}

initiator of the coagulation cascade. TF activates factor VIla creating an enzymatic complex that activate factor $X$ and factor IX. Factor IXa also activates factor $X$, in the presence of its cofactor factor VIIla. Factor $\mathrm{Xa}$, also in the presence of its cofactor factor $\mathrm{Va}$, then activates prothrombin to generate thrombin (lla) that cleaves soluble fibrinogen to generate insoluble fibrin that forms a crosslinked fibrin mesh at the site of an injury. Fibrin generation occurs simultaneously to platelet aggregation. Thrombin also plays an important role in down regulation of the coagulation cascade by binding to thrombomodulin on endothelial cells and then activating protein $\mathrm{C}$ (APC). The activated protein $\mathrm{C}$ anticoagulant system, with the cofactor protein $\mathrm{S}$, is important for the down regulation of the coagulation cascade, inactivating the procoagulant cofactors VIIla and Va. The coagulation cascade is also down-regulated by other physiological inhibitors of blood coagulation: antithrombin, that inhibits thrombin and factor Xa as well as factor IXa and factor Xla; heparin cofactor II (thrombin inhibitor) and tissue factor pathway inhibitor (TFPI), that inhibits factor $X a$.

The fibrinolytic system acts to dissolve and remove the clot formed from the injured tissue. The end product of this pathway, plasmin, is a potent enzyme that cleaves fibrin and this generates fibrin degradation products (FDPs), including D-dimer ${ }^{11}$.

The main age-related changes of the vascular system can be considered within the context of the classic Virchow triad (abnormal vessel wall, abnormal blood flow, and abnormal blood constituents). In addition, there are several changes in the hemostatic system, including coagulation and fibrinolytic factors ${ }^{12}$, that contribute to create a hypercoagulability of the blood with an increased incidence of thrombosis in the older people. Furthermore, while changes in hemostasis pathways commonly occur in the general population with aging, some components of this procoagulant status may also support the inflammatory processes that characterize advancing age, since markers such as factor VIII and fibrinogen, are acute-phase proteins ${ }^{13}$ the plasma concentrations of many coagulation factors (e.g., fibrinogen, factor [F] V, FVII, FVIII, and FIX (Fig. 1).

\section{INFLAMMATION, THROMBOSIS AND AGING}

Older people are frequently affected by multiple morbidities that are established prothrombotic risk factors, such as congestive heart failure, chronic obstructive disease, diabetes, cancer, chronic venous insufficiency ${ }^{14}$. Advanced age is also associated with an increase of inflammatory state that may be another important stimulus for thrombus formation, but the causal pathways and molecular mechanisms that connect inflammaging 


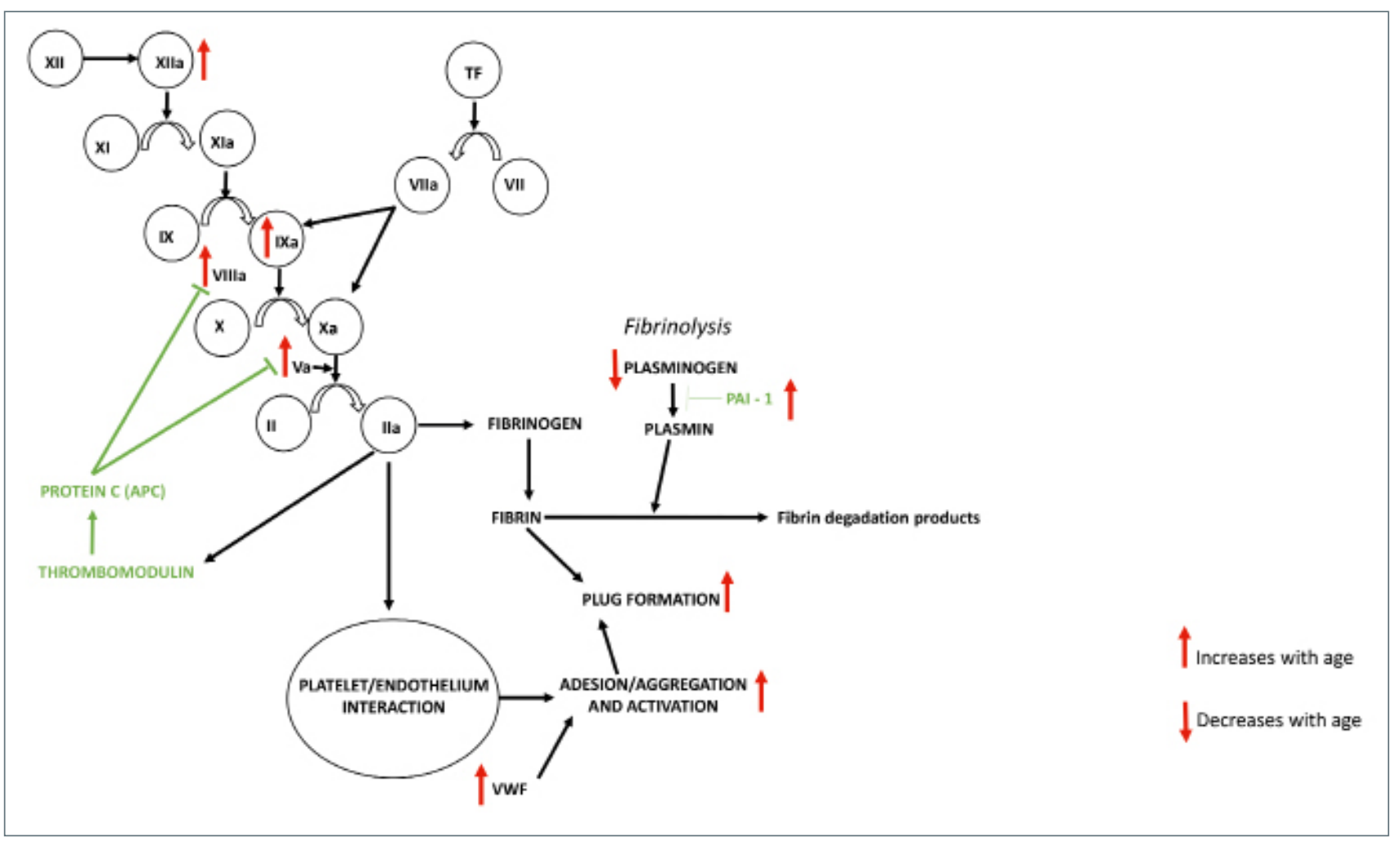

Figure 1 Age-related changes in hemostasis pathway.

and chronic diseases are not well understood. Two major hypotheses concerning the involvement of chronic inflammation in aging have been proposed: molecular inflammation and inflammaging ${ }^{15}$. The molecular inflammation hypothesis is based on molecular changes in inflammation-related transcription factors and in the expression levels of their target genes. The hypothesis states that these changes are the mechanism underlying the aging process and age-related diseases ${ }^{16,17}$. Prolonged oxidative stress and compromised antioxidant defense systems during aging are blamed for increased reactive species (RS), including reactive oxygen species (ROS), reactive nitrogen species (RNS), and reactive lipid aldehydes ${ }^{18}$. Although young organisms have a well-functioning antioxidant system to maintain redox balance, the age-related decline in the anti-oxidant defense leads to failure to maintain redox homeostasis, with activation of various proinflammatory signaling pathways. The Inflammaging hypothesis is based on the commonly observed age-associated increase in pro-inflammatory cytokines ${ }^{19}$. This concept states that activation of the innate immune system in older individuals leads to a dysregulation in inflammation that impairs the ability to initiate an efficient innate and adaptive immune program in responses to antigens or environmental stimuli ${ }^{20}$. According to this hypothesis, these alterations in the immune system contribute to the development of overt organ-specific inflammatory diseases such as atherosclerosis, hypercoagulability, Alzheimer's disease, and diabetes ${ }^{21}$. Clinically, inflammaging is characterized by increased blood levels of several inflammatory biomarkers, including c-reactive protein (CRP), IL-6, IL-18 and tumor necrosis factor- $\alpha$ (TNF- $\alpha$ ). In particular, IL-6 is a critical factor in the acute phase of inflammation and also upregulates the synthesis of hemostatic factors, such as fibrinogen ${ }^{22}$. IL-6 may also directly activate platelets, leading to platelet aggregation with a faster thrombus formation ${ }^{23}$.

Another element that may promote thrombo-inflammatory responses is an amplified platelet-monocyte interactions due to monocyte phenotype and function that are different in older adults than in younger adults ${ }^{24}$. In healthy individuals, about $95 \%$ of circulating monocytes display the cell surface antigen CD14 and, the remining smaller fraction of monocytes express CD16, with a pattern CD14high/CD16low. It has been demonstrated that acute systemic inflammation ${ }^{25}$, but also aging, are associated with a shift toward proinflammatory monocytes pattern CD14low/CD16high ${ }^{24}$. For example, Seidler at al. showed in a cohort of 181 healthy adults aged 18 to 88 , that pattern of CD14low/ CD16high monocyte counts increased with age and 
demonstrated altered surface protein and chemokine receptor expression ${ }^{26}$. Also Sadeghi et al. showed in a smaller study of nursing home residents that CD14low/ CD16high monocytes produced higher levels of proinflammatory cytokines ${ }^{27}$.

\section{CHANGES IN VASCULAR SYSTEM AND PLATELETS}

The peculiar aspects that characterize the aging of the vascular system include changes in the microcirculation, loss of vein structural integrity, stiffness and dilation of the arteries due to the degeneration of elastic fibers and the increase in collagen content ${ }^{28}$ and gradual development of endothelial dysfunction. All these changes can increase the risk for thrombosis in older people. The aged blood vessels also express less endothelial nitric oxide (NO) synthase ${ }^{29}$, resulting in less NO production ${ }^{30}$. Decreased NO production may contribute to increased platelet activation and arterial thrombosis ${ }^{31}$ as well as enhanced atherogenesis ${ }^{32}$.

Age-related changes in platelet count and function have also been documented. Comparing platelet count of a large population of older people with that of children, Balduini et al. ${ }^{33}$ showed a reduction of $35 \%$ in males and $25 \%$ in females. A correlation between platelet count and age was also found in a large study including 12.142 American subjects showing an average decrease of $7 \times 10^{3}$ platelets $/ \mu \mathrm{L}$ and of $18 \times 10^{3}$ platelets $/ \mu \mathrm{L}$ in individuals in the 60-69 year age group and 69 to 90 years, respectively, compared with those in the 20-59 years age group ${ }^{34}$. This phenomenon of age-related changes in platelet count has no explanation yet. It has been suggested a reduction of stem cell reserve in older people or a survival advantage of subject with lower platelet count in reaching older age ${ }^{34}$. In contrast, with advancing age there is a platelet hyperactivity: bleeding time, a measure of platelet aggregation responses, decreases significantly denoting a greater aggregation with a faster thrombus formation ${ }^{35}$. The mechanisms of this age-related platelet hyperactivity is unclear. Bastyr et al. have tested the hypothesis that the increase of platelet activity with age can be associated with a higher content of platelet phospholipids, suggesting an age-related alteration in platelet transmembrane signaling or second messenger accumulation ${ }^{36}$. Markers of platelet activation, $\beta$-thromboglobulin (a protein stored in platelet a granules) and platelet factor 4 (a key platelet receptor), are significantly elevated in older compared with younger people ${ }^{37}$. Furthermore, with advancing age there is a progressive decline of glutathione peroxidase-3 (GPx3), an antioxidant enzyme, contributing to vascular damage and endothelial disfunction ${ }^{38}$. It has been shown that a deficiency of GPx3, increases platelet activation with a consequent high risk of thrombotic events ${ }^{39,40}$.

Moreover, with advancing age platelets are less susceptible to inhibition by prostacyclin and have reduced surface prostacyclin receptors density ${ }^{24}$. Thus, altered activity of platelets contribute to increase the risk of thrombotic disorders in older subjects.

\section{CHANGES IN PROCOAGULANT, ANTICOAGULANT AND FIBRINOLYTIC SYSTEM PROTEINS}

Plasma concentrations of several coagulation proteins, including fibrinogen, factors V, VII, VIII, IX and XII, increase with advancing aging ${ }^{13}$. In contrast, concentrations of FX and prothrombin do not change significantly throughout the lifetime ${ }^{41}$.

Elevated levels of fibrinogen have been described as a recognized risk factor for thrombotic disorders ${ }^{42}$, even if the mechanism by which fibrinogen contribute to increase cardiovascular risk have not been elucidated. In particular, fibrinogen levels have been shown to increase with age. Kannel et al. demonstrated in the Framingham study that the mean plasma level of fibrinogen increased from about $280 \mathrm{mg} / \mathrm{dL}$ in individuals aged 47-54 years to over $300 \mathrm{mg} / \mathrm{dL}$ in individuals aged 65-79 years ${ }^{42}$. In a population study, people aged 53-64 years showed significantly higher levels $(300 \mathrm{mg} /$ $\mathrm{dL})$ than subjects 20 years old $(250 \mathrm{mg} / \mathrm{dL}){ }^{43}$. Thus, an increment of plasma fibrinogen level by $10 \mathrm{mg} / \mathrm{dL}$ for each decade can be expected in healthy subjects ${ }^{13}$.

Factor VIII progressively increase with age, reaching a mean of over $200 \mathrm{U} / \mathrm{dL}$ in the seventh decade of life ${ }^{44}$, and it is associated with an approximately fivefold increased risk of venous thrombosis when exceeding $150 \mathrm{U} / \mathrm{dL}^{45}$. Ofosu et al. demonstrated age-related changes in FVII proteolysis in normal individuals with a consequent increase in the concentrations of activated FVII, FVII zymogen, total FVII-related proteins, tissue factor pathway inhibitor (TFPI), and prothrombin fragments $1+2{ }^{46}$ Thus, the authors hypothesized that these could lead to increased thrombin generation in vivo, with a possible explanation of the high thrombotic risk in older people. Furthermore, FVII has been described as an important risk factor for cardiovascular events in the Prospective Cardiovascular Münster study ${ }^{47}$, in particular when associated with additional cardiovascular risk factors, such as smoking, myocardial infarction events in family, angina pectoris, high levels of fibrinogen, total cholesterol, LDL cholesterol, and triglycerides, and a low level of HDL cholesterol. In contrast, the Cardiovascular Health Study (CHS), which analyzes 5888 white and African American men and women aged $\geq 65$ years, 
found an association with cardiovascular events for high levels of fibrinogen and FVIII, but not of FVII. It is likely that methodological differences between the studies might explain this discrepancy ${ }^{48}$.

Among prothrombotic factors, it has been found that also levels of von Willebrand factor (NWF) increases with aging contributing to higher incidence of thromboembolic disease in older people ${ }^{6}$. Moreover, it has been showed that ADAMTS13, a metalloproteinase that cleaves WWF preventing its accumulation, does not increase in a parallel fashion, with a consequent additional shift toward the prothrombotic state ${ }^{49}$.

As far as anticoagulant factors are concerned, the available evidences about their changes with age are contrasting. Favaloro et al. showed small but significant age-related increases in protein $\mathrm{C}$ activity, and in total and free protein $\mathrm{S}$, but also a reduction in plasma concentration of antithrombin ${ }^{50}$. In contrast, Bauer et al found no change in antithrombin and protein $C$ levels with aging in men aged 21 to 81 years ${ }^{51}$.

With respect to the fibrinolytic system, it has been described a reduction in plasminogen levels in subjects aged 75 years or older ${ }^{52}$, but another study reported that plasminogen levels decreased slightly with age in women but not in men ${ }^{53}$. In contrast, plasminogen activator inhibitor (PAI)-1, which is the major inhibitor of fibrinolysis, increased with advancing age ${ }^{14}$. In particular, PAl-1 is an acute phase reactant influenced by several cytokines, including IL- 6 , TNF- $\alpha$, TGF- $\beta$ and hormones, and its expression is related to stress-induced thrombosis in older people. Indeed, Yamamoto et al. demonstrate in aged mice that stress causes a thrombotic tendency in an age-associated manner, and this result correlates with the large induction of PAl-1 expression ${ }^{54}$.

\section{THE PARADOX OF HYPERCOAGULABILITY IN OLDER POPULATION}

While being at first glance a detrimental effect of aging, age-related changes in the coagulation system may also have beneficial and compensatory effects, such as against tumor growth and metastasis ${ }^{6}$. In fact, several coagulation products act as inhibitors of angiogenesis ${ }^{55,56}$. These include domain 5 of high-molecular-weight kininogen, a cleaved form of antithrombin, prothrombin fragment $1+2(\mathrm{~F} 1+2)$, and angiostatin, a derivative of plasminogen. Platelet products, including PF4, PAl-1, and thrombospondin-1, are also inhibitors of angiogenesis ${ }^{56}$. Thus, a higher propensity for thrombosis, although potentially detrimental in patients with atherosclerosis, may confer a survival advantage by inhibiting tumor-associated angiogenesis in the elderly population.

\section{THROMBOPROPHYLAXIS AND RISK OF BLEEDING IN OLDER POPULATION}

The increased thrombotic risk make the older patient a theoretical target for anticoagulant therapy, but the concomitant risk of major bleeding (intracranial bleeding or fatal hemorrhages) make the use of this drugs problematic, with consequent underuse ${ }^{57}$. Older patients who take anticoagulants have an almost 2-fold increased risk of anticoagulation-related major and clinically relevant non-major bleeding than younger patients ${ }^{9}$, possibly due to the higher prevalence of concomitant diseases, drug interactions, and age-related conditions. The multicenter, prospective Registro Informatizado de Enfermedad TromboEmbólica (RIETE) showed an increased rate of bleeding during anticoagulation therapy in patients aged $\geq 80$ years old with acute VTE followed for at least three months after diagnosis compared to younger patients ${ }^{58}$. Vasco et al. ${ }^{59}$ described that in a subgroup of 610 people aged $\geq 90$ years from the same RIETE registry, $4.9 \%$ had major bleeding complications, more than half fatal. Finally, the Worcester Venous Thromboembolism Study showed increased incidence rates of major bleedings in patients aged $\geq 65$ years versus those $<65$ years $(9.2$ and $4.8 \%$, respectively) at 30 days after an acute episode of VTE. At 1 year, these proportions increased to 13.2 and $6.6 \%$ in older and younger people, respectively, with more than $50 \%$ of all major bleeding episodes occurring within 1 month of VTE diagnosis ${ }^{7}$. Nevertheless, also the benefits in administering anticoagulants are increased in consideration of the high propensity of older subjects to hypercoagulability with a consequent higher risk of thrombosis. Thus, anticoagulants should be administered when indicated, such as prevention from stroke in older patients with atrial fibrillation (AF) or prevention of VTE expansion and recurrence in particular in older people with reduced mobility.

A further complication in using anticoagulation in older patients come from the fact that this population is underrepresented in many clinical trials of TE and of anticoagulant therapy ${ }^{7}$ due to co-morbid conditions, short life expectancy, long-term immobility or contraindications to therapy ${ }^{60}$. As a consequence, treatment regimens derived from the results from clinical trials might not be optimal for older patients.

One of the most common indications to anticoagulants is atrial fibrillation (AF) in order to prevent stroke, since patients with AF have a 5 -fold higher risk of ischemic stroke compared to healthy subjects, and the rate of thromboembolic events is substantially higher in the older people ${ }^{61}$. An effective stroke prevention requires long-term use of oral anticoagulant with vitamin $\mathrm{K}$ antagonists (VKAs) or direct oral anticoagulants (DOACs) 
and this evidence comes from randomized controlled trials (RCTs) demonstrating that warfarin reduces stroke/systemic embolism by $67 \%$, ischemic stroke by $65 \%$, and all-cause mortality by $26 \%$ compared with placebo or control ${ }^{62}$. This evidence has also been confirmed in the BAFTA trial, which specifically investigated older patients with $A F \geq 75$ years, randomized to warfarin or aspirin $75 \mathrm{mg}$, and showed that warfarin significantly reduced thromboembolism by $>50 \%$, with no significant difference between warfarin and aspirin for major bleeding or intracranial bleeding ${ }^{63}$. Nonetheless, few studies including very old subjects are available. Chao et al. investigated the risk of ischemic stroke and intracranial hemorrhage $(\mathrm{ICH})$ and the net clinical benefit of oral anticoagulant treatment for very old patients with AF ( $\geq 90$ years of age), demonstrating that antiplatelet agents were ineffective for stroke prevention and were not safer than no antithrombotic therapy; warfarin was associated with a positive net clinical benefit when compared to no antithrombotic therapy or antiplatelet drugs. Moreover, compared with warfarin, DOACs were associated with a lower risk of $\mathrm{ICH}$, with no difference in risk of ischemic stroke ${ }^{64}$. DOACs (apixaban, dabigatran, edoxaban and rivaroxaban) showed an improved risk-benefit profile in non-valvular AF patients as demonstrated by the lower incidence of stroke, intracranial hemorrhage, and death compared to warfarin ${ }^{65}$. These agents are currently considered an alternative for VKAs to prevent stroke in patients with $\mathrm{AF}$ and have emerged as the preferred choice, particularly in patients newly started on anticoagulation ${ }^{66}$. Additional evidence of efficacy and safety of DOACs came from a meta-analysis including 22 studies enrolling 440,281 AF patients $\geq 75$ years that showed a reduction of the risk of stroke and systemic embolism compared to VKAs, although a comparable global incidence of major bleedings. In particular, DOACs reduced the rate of intracranial bleeding and hemorrhagic stroke events compared to VKAs, but increased the rate of Gl bleedings, particularly rivaroxaban and dabigatran ${ }^{67}$. Finally, a greater benefit of DOACs over VKA therapy has been found in subgroup analyses in subjects aged over 75 years, in patients with renal insufficiency (creatinine clearance $30-50 \mathrm{~mL} / \mathrm{min}$ ) and in those with a history of falls 68 .

As far as VTE is concerned, all older patients with acute VTE and without any absolute contraindication to anticoagulation should receive active anticoagulant treatment as soon as diagnosis has been made, and even before in case of high clinical probability ${ }^{58}$. This is important to prevent VTE expansion and recurrence. According to the new acute pulmonary embolism (PE) guidelines, the anticoagulant therapy should last no less than 3 months with the recommendation of an indefinite duration of treatment for patients presenting with recurrent VTE ${ }^{69}$. Once again, these indications are based on evidence coming from clinical trials not including older patients; thus, selection of the optimal antithrombotic agent, its dose, and duration of treatment is particularly difficult in this population. Anyway, during the last decade, DOACs have taken the place of VKAs in acute and long-term VTE treatment due to the convenience of administration and an excellent dose-response relationship without the need for monitoring or frequent dose adjustments ${ }^{70}$. Indeed, the few reviews examining study evidence on DOACs compared to VKAs for VTE treatment in patients $\geq 75$ years of age have demonstrated better efficacy and safety of DOACs over VKAs, with no increase in the risk of bleeding ${ }^{71,72}$.

It must be noted that individual DOAC may have different profiles with respect to both effectiveness and safety. In the AMPLIFY study, apixaban (10 mg twice daily for seven days, then $5 \mathrm{mg}$ twice daily for six months) was non inferior to warfarin bridged with enoxaparin in reduction of VTE in both the older and total patient population ${ }^{73}$. The RE-COVER II trial found that dabigatran $150 \mathrm{mg}$ twice daily was non inferior to warfarin, in reducing the risk of recurrent VTE in the older population ${ }^{74}$. The Hokusai-VTE study, comparing edoxaban to warfarin, observed a significant reduction in risk of VTE compared with warfarin in the older patient population ${ }^{75}$. In the EINSTEIN-DVT and PE trials rivaroxaban (15 $\mathrm{mg}$ twice daily for three weeks, then $20 \mathrm{mg}$ once daily) was non inferior to warfarin bridged with enoxaparin in the reduction of VTE in both elderly populations and in the total patient population ${ }^{76}$. Finally, in a meta-analysis of AF randomized controlled trials, DOACs reduced the risk of stroke or systemic thromboembolism by $19 \%$ compared with warfarin, largely due to a markedly lower rate of hemorrhagic stroke and intracranial bleeding (ICB) ${ }^{65}$. As far as safety profiles concerned, it has been shown a significant reduction in risk of major bleeding for older patients taking apixaban or rivaroxaban compared to warfarin ${ }^{73,76}$. In contrast, there was a non-significant difference in major bleeding for dabrigatran and edoxaban compared with warfarin in the older and in the total patient population ${ }^{74,75}$. In addition to these studies, very few real world studies have been conducted to compare the safety and effectiveness between DOACs focusing on very old patients. Deitelzweig et al. showed in a retrospective observational study of 88582 very old patients (aged $\geq 80 y$ ) with non-valvular AF that apixaban was associated with a lower risk of stroke/systemic embolism (SE), major bleeding (MB) and all cause mortality compared with dabigatran and rivaroxaban ${ }^{77}$. A significant increase in the risk of gastrointestinal (Gl) bleeding was observed in two randomized trials evaluating dabigatran and 
rivaroxaban in AF patients: in the RE-LY trial the authors showed that dabigatran $150 \mathrm{mg}$ bid (but not dabigatran $110 \mathrm{mg}$ bid) was significantly associated with increased risk of major $\mathrm{Gl}$ bleeding compared with warfarin ${ }^{78}$, whereas in the ROCKET-AF trial, rivaroxaban $20 \mathrm{mg}$ once daily increased this annual risk by $1 \%{ }^{79}$. DOACassociated Gl bleeding is probably related to the presence of the active drug in the Gl tract thus facilitating bleeding from vulnerable lesions ${ }^{80}$. Thus, in patients with AF at a high-risk of Gl bleeding, the 2016 European Society of Cardiology guidelines recommend using VKAs or DOACs other than dabigatran at a dose of $150 \mathrm{mg}$ bid, rivaroxaban, $20 \mathrm{mg}$ once daily, and edoxaban, $60 \mathrm{mg}$ once daily ${ }^{81}$.

An additional increased risk of bleeding in using DOACs is related to the possible presence of renal dysfunction, underweight or drugs interaction that are common among older subjects.

Currently, all DOACs have been approved for use in patients with chronic kidney disease (CKD) up to stage III. For patients with $\mathrm{CrCl}<30$ and $>15 \mathrm{ml} / \mathrm{min}$, apixaban, rivaroxaban and edoxaban have been approved (with dose adjustement), while use of dabigatran is not recommended. In the European Union, none of the DOAC is indicated when $\mathrm{CrCl}$ is less than $15 \mathrm{ml} / \mathrm{min}$ or in patients undergoing hemodialysis, while for the latter group the FDA approved the use of apixaban and rivaroxaban (Tab. II) ${ }^{82}$.

Being underweight has also been associated with an increased risk of major bleeding in patients taking oral anticoagulants, but there are still few evidences in this population, with consequent contrasting data. In fact, Park et al. showed, in an AF population taking DOACs according to their body mass index (BMI), an increased risk of major bleeding and all-cause death in underweight patients, defined by $\mathrm{BMl}<18.5$, compared with being normal weight or obese. However, the median body weight in the low BMl group was $63.9 \mathrm{~kg}$ and the authors underline that a body weight $<60 \mathrm{~kg}$ was not an independent predictor of bleeding events ${ }^{83}$. More recently Lee et al. showed, in a large real-world Korean cohort with low body weight $(<60 \mathrm{~kg})$ taking oral anticoagulants, that DOACs are better effectiveness and safety than warfarin both with regular and reduced dosage ${ }^{84}$. However, guidelines suggest caution with the use of non-vitamin $\mathrm{K}$ antagonist oral anticoagulants in patients with low body weight $(<60 \mathrm{~kg})$ because of lack of evidences in this population (Tab. II).

Finally, polypharmacy, that is very frequent among older people, in addition to anticoagulant therapy may increase the risk of bleeding. Current knowledge of drug-drug interactions associated with DOACs mainly comes from animal studies, case reports, and limited pharmacokinetic measurement ${ }^{85}$. All the DOACs are substrates of P-glycoprotein (P-gp), and inhibition of this enzyme may increase bleeding risk. Thus, using a DOAC with P-gp inhibitors, such as ketoconazole and verapamil, or inducers, such a rifampin, may respectively increase or reduce the anticoagulant effect. In addition, rivaroxaban and apixaban also undergo metabolism to an extent of $40 \%-50 \%$ in the liver through the cytochrome P450 (CYP) pathway, specifically via CYP3A4, with a consequent possible interaction with drugs that induce or inhibit these pathways ${ }^{86}$ (Tab. II). VTE is of particular concern in patients admitted to hospital wards with acute medical conditions. In this population, patients aged $>75$ years have an approximately 2-fold increased short-term risk of VTE than younger

Table II. DOACs special recommendation.

\begin{tabular}{|c|c|c|c|}
\hline Anticoagulant & $\%$ Renal elimination & Drug interaction & Recommendation for dose reduction \\
\hline Apixaban & 25 & CYp3A4; P-gp & $\begin{array}{l}2.5 \mathrm{mg} \text { BID if: } \\
\text { - Age }>80 \text { years } \\
\text { - Weight }<60 \mathrm{~kg} \\
\text { - } \mathrm{CrCl} 15-30 \mathrm{ml} / \mathrm{min} \\
\text { - Not recommended if } \mathrm{CrCl}<15 \mathrm{ml} / \mathrm{min}\end{array}$ \\
\hline Rivaroxaban & 67 & CYp3A4; P-gp & $\begin{array}{l}15 \mathrm{mg} \text { QD if: } \\
\text { - } \mathrm{CrCl} 15-50 \mathrm{ml} / \mathrm{min} \\
\text { - Not recommended if } \mathrm{CrCl}<15 \mathrm{ml} / \mathrm{min}\end{array}$ \\
\hline Dabigatran & 80 & P-gp & $\begin{array}{l}75 \mathrm{mg} \text { QD if: } \\
\text { - } \mathrm{CrCl} 30-50 \mathrm{ml} / \mathrm{min} \\
\text { - Not recommended if } \mathrm{CrCl}<30 \mathrm{ml} / \mathrm{min} \\
\text { - Age }>75 \text { years }\end{array}$ \\
\hline Edoxaban & 35 & P-gp & $\begin{array}{l}30 \mathrm{mg} \mathrm{QD} \text { : } \\
\text { - } \mathrm{CrCl} 15-50 \mathrm{ml} / \mathrm{min} \\
\text { - not recommended if } \mathrm{CrCl}<15 \mathrm{ml} / \mathrm{min} \\
\text { - Weight }<60 \mathrm{~kg}\end{array}$ \\
\hline
\end{tabular}


patients ${ }^{9}$. Current guidelines recommend prophylaxis with fondaparinux or LMWH in high-risk hospitalized medical patients $>70$ years to prevent VTE ${ }^{87}$. Because age over 75 years is an independent risk factor of VTE in medically ill patients ${ }^{88}$ the presence of only one additional acute medical condition, such as acute myocardial infarction, acute heart failure, active cancer requiring therapy, acute infectious disease, respiratory disease etc., is required to consider thromboprophylaxis for these patients ${ }^{89}$. However, a recent case-control study conducted in France showed that in patients $<75$ years there was a 2-fold increase in VTE in patients not receiving anticoagulants compared to those treated, while in patients $>75$ years of age there were not differences in VTE risk in those taking or not taking anticoagulants ${ }^{90}$. Thus, the authors agreed that thromboprophylaxis should only be prescribed following careful benefitrisk assessments, and that it is essential to consider major and non-major bleeding risks and comorbidities, including renal function, hypertension, infections and coronary artery disease.

In this context, The Padua Prediction Score (PPS) and the Improve Bleeding Score (IBS) have been approved by The American College of Chest Physicians $9^{\text {th }}$ Edition guidelines as validated tools for VTE risk assessment in hospitalized old medical patients ${ }^{91}$. Some data suggest that a positive PPS and IBS are associated with early mortality in Internal Medicine patients ${ }^{92}$, but it has been demonstrated, in a group of old hospitalized patients, that their additional predictive accuracy is modest (positive PPS sensitivity: 96.67\%, specificity: $20.74 \%$; IBS sensitivity: $20.88 \%$, specificity: $90.45 \%)$, resulting not very useful in clinical practice ${ }^{93}$. Anyway, few studies about using these models in very old subjects are available.

\section{CONCLUSIONS}

This narrative review showed age-related changes of hemostasis pathways in older subjects, that can be considered as a normal phenomenon of aging, but may also be a consequence of dysregulated inflammatory pathways that contribute, together with multiple morbidities that are established prothrombotic risk factors, to increase the risk of thrombo-inflammatory disease in this population. Among the thrombotic cardiovascular diseases, stroke prevention remains one of the most important indication to use of anticoagulants even among very old and studies demonstrated the safety and efficacy of DOACs in terms of reduced risk of bleeding compared with warfarin. Anyway, despite the higher incidence, morbidity and mortality of TE in older subjects, a relevant proportion of this population do not receive prophylaxis with anticoagulants. In this context, a tailored therapy in older people should be necessary taking into consideration changes attributed to aging and medical background in order to evaluate risk-benefit ratio in administering the potential optimal anticoagulant therapy.

\section{References}

1 Tracy RP, Bovill EG. Thrombosis and cardiovascular risk in the elderly. Arch Pathol Lab Med 1992;116:1307-12.

2 Benjamin EJ, Muntner P, Alonso A, et al. Heart disease and stroke statistics - 2019 update: a report from the American Heart Association. Circulation 2019;139. https://doi. org/10.1161/CIR.0000000000000659

3 Kung $\mathrm{H}-\mathrm{C}$, Hoyert DL, Xu J, et al. Deaths: final data for 2005. Natl Vital Stat Rep 2008;56:1-120.

4 Benjamin EJ, Blaha MJ, Chiuve SE, et al. Heart disease and stroke statistics - 2017 update: a report from the American Heart Association. Circulation 2017;135:e146603. https://doi.org/10.1161/CIR.0000000000000485

5 Naess IA, Christiansen SC, Romundstad P, et al. Incidence and mortality of venous thrombosis: a population-based study. J Thromb Haemost 2007;5:692-9. https://doi. org/10.1111/j.1538-7836.2007.02450.x

6 Wilkerson WR, Sane DC. Aging and thrombosis. Semin Thromb Hemost 2002;28:555-68. https://doi. org/10.1055/s-2002-36700

7 Spencer FA, Gore JM, Lessard D, et al. Venous thromboembolism in the elderly. A community-based perspective. Thromb Haemost 2008;100:780-8.

8 Faller N, Limacher A, Méan M, et al. Predictors and causes of long-term mortality in elderly patients with acute venous thromboembolism: a Prospective Cohort study. Am J Med 2017;130:198-206. https://doi.org/10.1016/j.amjmed.2016.09.008

9 Tritschler T, Aujesky D. Venous thromboembolism in the elderly: a narrative review. Thromb Res 2017;155:140-147. https://doi.org/10.1016/j.thromres.2017.05.015

10 Cushman M. Epidemiology and risk factors for venous thrombosis. Semin Hematol 2007;44:62-9. https://doi. org/10.1053/j.seminhematol.2007.02.004

11 Gale AJ. Current understanding of hemostasis. Toxicol Pathol 2011;39:273-80. https://doi. org/10.1177/0192623310389474

12 Yamamoto K, Takeshita K, Kojima T, et al. Aging and plasminogen activator inhibitor-1 (PAl-1) regulation: implication in the pathogenesis of thrombotic disorders in the elderly. Cardiovasc Res 2005;66:276-85. https://doi. org/10.1016/j.cardiores.2004.11.013

13 Favaloro EJ, Franchini M, Lippi G. Aging hemostasis: changes to laboratory markers of hemostasis as we age - a narrative review. Semin Thromb Hemost 2014;40:621 33. https://doi.org/10.1055/s-0034-1384631

14 Tzoran I, Hoffman R, Monreal M. Hemostasis and thrombosis in the oldest old. Semin Thromb Hemost 2018;44:62431. https://doi.org/10.1055/s-0038-1657779

15 Chung HY, Kim DH, Lee EK, et al. Redefining chronic 
inflammation in aging and age-related diseases: proposal of the senoinflammation concept. Aging Dis 2019;10:36782. https://doi.org/10.14336/AD.2018.0324

16 Chung HY, Kim HJ, Kim KW, et al. Molecular inflammation hypothesis of aging based on the anti-aging mechanism of calorie restriction. Microsc Res Tech 2002;59:264-72. https://doi.org/10.1002/jemt.10203

17 Chung HY, Lee EK, Choi YJ, et al. Molecular inflammation as an underlying mechanism of the aging process and age-related diseases. J Dent Res 2011;90:830-40. https://doi.org/10.1177/0022034510387794

18 Chung HY, Sung B, Jung KJ, et al. The molecular inflammatory process in aging. Antioxid Redox Signal 2006;8:57281. https://doi.org/10.1089/ars.2006.8.572

19 Franceschi C, Campisi J. Chronic inflammation (inflammaging) and its potential contribution to age-associated diseases. J Gerontol A Biol Sci Med Sci 2014;69(Suppl 1):S4-9. https://doi.org/10.1093/gerona/glu057

20 Baylis D, Bartlett DB, Patel HP, et al. Understanding how we age: insights into inflammaging. Longev Healthspan 2013;2:8. https://doi.org/10.1186/2046-2395-2-8

21 Bauer ME, Fuente MD. The role of oxidative and inflammatory stress and persistent viral infections in immunosenescence. Mech Ageing Dev 2016;158:27-37. https://doi. org/10.1016/j.mad.2016.01.001

22 Ershler WB. Interleukin-6: a cytokine for gerontologists. J Am Geriatr Soc 1993;41:176-81. https://doi. org/10.1111/j.1532-5415.1993.tb02054.x

23 Oleksowicz L, Mrowiec Z, Zuckerman D, et al. Platelet activation induced by interleukin-6: evidence for a mechanism involving arachidonic acid metabolism. Thromb Haemost 1994;72:302-8.

24 Mohebali D, Kaplan D, Carlisle M, et al. Alterations in platelet function during aging: clinical correlations with thromboinflammatory disease in older adults. J Am Geriatr Soc 2014;62:529-35. https://doi.org/10.1111/jgs.12700

25 Ziegler-Heitbrock L. The CD14+ CD16+ blood monocytes: their role in infection and inflammation. J Leukoc Biol 2007;81:584-92. https://doi.org/10.1189/jlb.0806510

26 Seidler S, Zimmermann HW, Bartneck M, et al. Age-dependent alterations of monocyte subsets and monocyterelated chemokine pathways in healthy adults. BMC Immunol 2010;11:30. https://doi.org/10.1186/1471-2172$11-30$

27 Sadeghi HM, Schnelle JF, Thoma JK, et al. Phenotypic and functional characteristics of circulating monocytes of elderly persons. Exp Gerontol 1999;34:959-70. https:// doi.org/10.1016/s0531-5565(99)00065-0

28 Celermajer DS, Sorensen KE, Bull C, et al. Endotheliumdependent dilation in the systemic arteries of asymptomatic subjects relates to coronary risk factors and their interaction. J Am Coll Cardiol 1994;24:1468-74. https:// doi.org/10.1016/0735-1097(94)90141-4

29 Chou TC, Yen MH, Li CY, et al. Alterations of nitric oxide synthase expression with aging and hypertension in rats. Hypertension 1998;31:643-8. https://doi.org/10.1161/01. hyp.31.2.643
30 Taddei S, Virdis A, Ghiadoni L, et al. Age-related reduction of $\mathrm{NO}$ availability and oxidative stress in humans. Hypertension 2001;38:274-9. https://doi.org/10.1161/01. hyp.38.2.274

31 Loscalzo J. Nitric oxide insufficiency, platelet activation, and arterial thrombosis. Circ Res 2001;88:756-62. https:// doi.org/10.1161/hh0801.089861

32 Garg UC, Hassid A. Nitric oxide-generating vasodilators and 8-bromo-cyclic guanosine monophosphate inhibit mitogenesis and proliferation of cultured rat vascular smooth muscle cells. J Clin Invest 1989;83:1774-7. https://doi. org/10.1172/JCl114081

33 Balduini CL, Noris P. Platelet count and aging. Haematologica 2014;99:953-5. https://doi.org/10.3324/haematol.2014.106260

34 Segal JB, Moliterno AR. Platelet counts differ by sex, ethnicity, and age in the United States. Ann Epidemiol 2006;16:123-30. https://doi.org/10.1016/j.annepidem.2005.06.052

35 Le Blanc J, Lordkipanidzé M. Platelet function in aging. Front Cardiovasc Med 2019;6:109. https://doi. org/10.3389/fcvm.2019.00109

36 Bastyr EJ, Kadrofske MM, Vinik Al. Platelet activity and phosphoinositide turnover increase with advancing age. Am J Med 1990;88:601-6. https://doi.org/10.1016/00029343(90)90525-i

37 Zahavi J, Jones NA, Leyton J, et al. Enhanced in vivo platelet "release reaction" in old healthy individuals. Thromb Res 1980;17:329-36. https://doi.org/10.1016/00493848(80)90067-5

38 Pastori D, Pignatelli P, Farcomeni A, et al. Aging-related decline of glutathione peroxidase 3 and risk of cardiovascular events in patients with atrial fibrillation. J Am Heart Assoc 2016;5. https://doi.org/10.1161/JAHA.116.003682

39 Jin RC, Mahoney CE, Coleman Anderson L, et al. Glutathione peroxidase-3 deficiency promotes platelet-dependent thrombosis in vivo. Circulation 2011;123:1963-73. https://doi.org/10.1161/CIRCULATIONAHA.110.000034

40 Zuo L, Prather ER, Stetskiv M, et al. Inflammaging and oxidative stress in human diseases: from molecular mechanisms to novel treatments. Int J Mol Sci 2019;20. https:// doi.org/10.3390/ijms20184472

41 Favaloro EJ, Soltani S, McDonald J, et al. Cross-laboratory audit of normal reference ranges and assessment of $\mathrm{ABO}$ blood group, gender and age on detected levels of plasma coagulation factors. Blood Coagul Fibrinolysis.2005;16:597-605. https://doi.org/10.1097/01. mbc.0000187250.32630.56

42 Kannel WB, Wolf PA, Castelli WP, et al. Fibrinogen and risk of cardiovascular disease. The Framingham Study. JAMA 1987;258:1183-6.

43 Meade TW, North WR, Chakrabarti R, et al. Populationbased distributions of haemostatic variables. Br Med Bull 1977;33:283-8. https://doi.org/10.1093/oxfordjournals. bmb.a071448

44 Lowe GD, Rumley A, Woodward M, et al. Epidemiology of coagulation factors, inhibitors and activation markers: 
the Third Glasgow MONICA survey. I. Illustrative reference ranges by age, sex and hormone use. $\mathrm{Br} \mathrm{J}$ Haematol 1997;97:775-84. https://doi.org/10.1046/j.13652141.1997.1222936.x

$45 \mathrm{~T} \mathrm{~K}, \mathrm{Ad} \mathrm{B}, \mathrm{E} \mathrm{B}, \mathrm{Jp}$ V, Fr R. Role of clotting factor VIII in effect of von willebrand factor on occurrence of deep-vein thrombosis. Lancet (London, England).

46 Ofosu FA, Craven S, Dewar L, et al. Age-related changes in factor VII proteolysis in vivo. Br J Haematol 1996;94:40712. https://doi.org/10.1046/j.1365-2141.1996.d01-1793.x

47 Ten Cate H, Meade T. The Northwick Park Heart study: evidence from the laboratory. J Thromb Haemost 2014;12:587-92. https://doi.org/10.1111/jth.12545

48 Tracy RP, Arnold AM, Ettinger W, et al. The relationship of fibrinogen and factors VII and VIII to incident cardiovascular disease and death in the elderly: results from the cardiovascular health study. Arterioscler Thromb Vasc Biol 1999;19:1776-83. https://doi.org/10.1161/01. atv.19.7.1776

49 Kokame K, Sakata T, Kokubo Y, et al. von Willebrand factor-to-ADAMTS13 ratio increases with age in a Japanese population. J Thromb Haemost 2011;9:1426-8. https:// doi.org/10.1111/j.1538-7836.2011.04333.x

50 Favaloro EJ, Soltani S, McDonald J, et al. Laboratory identification of familial thrombophilia: do the pitfalls exceed the benefits? A reassessment of $\mathrm{ABO}$-blood group, gender, age, and other laboratory parameters on the potential influence on a diagnosis of protein $\mathrm{C}$, protein $\mathrm{S}$, and antithrombin deficiency and the potential high risk of a false positive diagnosis. Lab Hematol 2005;11:174-84. https:// doi.org/10.1532/LH96.05029

51 Bauer KA, Weiss LM, Sparrow D, et al. Aging-associated changes in indices of thrombin generation and protein $\mathrm{C}$ activation in humans. Normative Aging Study. J Clin Invest 1987;80:1527-34. https://doi.org/10.1172/JCl113238

52 Hamilton PJ, Dawson AA, Ogston D, et al. The effect of age on the fibrinolytic enzyme system. J Clin Pathol 1974;27:326-9. https://doi.org/10.1136/jcp.27.4.326

53 Dolan G, Neal K, Cooper P, et al. Protein C, antithrombin III and plasminogen: effect of age, sex and blood group. $\mathrm{Br} J$ Haematol 1994;86:798-803. https://doi. org/10.1111/j.1365-2141.1994.tb04832.x

54 Yamamoto K, Takeshita K, Shimokawa T, et al. Plasminogen activator inhibitor-1 is a major stress-regulated gene: implications for stress-induced thrombosis in aged individuals. Proc Natl Acad Sci USA 2002;99:890-5. https:// doi.org/10.1073/pnas.022608799

55 Browder T, Folkman J, Pirie-Shepherd S. The hemostatic system as a regulator of angiogenesis. J Biol Chem 2000;275:1521-4. https://doi.org/10.1074/ jbc.275.3.1521

56 Folkman J, Browder T, Palmblad J. Angiogenesis research: guidelines for translation to clinical application. Thromb Haemost 2001;86:23-33.

57 Hylek EM, Evans-Molina C, Shea C, et al. Major hemorrhage and tolerability of warfarin in the first year of therapy among elderly patients with atrial fibrillation. Circulation
2007;115:2689-96. https://doi.org/10.1161/CIRCULATIONAHA. 106.653048

58 Palareti G, Poli D. The prevention of venous thromboembolism recurrence in the elderly: a still open issue. Expert Rev Hematol 2018;11:903-9. https://doi.org/10.1080/174 74086.2018.1526667

59 Vasco B, Villalba JC, Lopez-Jimenez L, et al. Venous thromboembolism in nonagenarians. Findings from the RIETE Registry. Thromb Haemost 2009;101:1112-8.

60 Lacruz B, Tiberio G, Núñez MJ, et al. Venous thromboembolism in centenarians: Findings from the RIETE registry. Eur J Intern Med 2016;36:62-6. https://doi.org/10.1016/j. ejim.2016.07.025

61 Lip GYH, Nieuwlaat R, Pisters R, et al. Refining clinical risk stratification for predicting stroke and thromboembolism in atrial fibrillation using a novel risk factor-based approach: the euro heart survey on atrial fibrillation. Chest 2010;137:263-72. https://doi.org/10.1378/chest.09-1584

62 Hart RG, Pearce LA, Aguilar MI. Meta-analysis: antithrombotic therapy to prevent stroke in patients who have nonvalvular atrial fibrillation. Ann Intern Med 2007;146:857-67. https://doi.org/10.7326/0003-4819-146-12-20070619000007

63 Mant J, Hobbs FDR, Fletcher K, et al. Warfarin versus aspirin for stroke prevention in an elderly community population with atrial fibrillation (the Birmingham Atrial Fibrillation Treatment of the Aged Study, BAFTA): a randomised controlled trial. Lancet 2007;370:493-503. https://doi. org/10.1016/S0140-6736(07)61233-1

64 Chao T-F, Liu C-J, Lin Y-J, et al. Oral anticoagulation in very elderly patients with atrial fibrillation: a Nationwide Cohort study. Circulation 2018;138:37-47. https://doi. org/10.1161/CIRCULATIONAHA.117.031658

65 Ruff CT, Giugliano RP, Braunwald E, et al. Comparison of the efficacy and safety of new oral anticoagulants with warfarin in patients with atrial fibrillation: a meta-analysis of randomised trials. Lancet 2014;383(9921):955-962. doi:10.1016/S0140-6736(13)62343-0

66 Steffel J, Verhamme P, Potpara TS, et al. The 2018 European Heart Rhythm Association Practical Guide on the use of non-vitamin $\mathrm{K}$ antagonist oral anticoagulants in patients with atrial fibrillation. Eur Heart J 2018;39:1330-93. https://doi.org/10.1093/eurheartj/ehy136

67 Silverio A, Di Maio M, Prota C, et al. Safety and efficacy of non-vitamin $\mathrm{K}$ antagonist oral anticoagulants in elderly patients with atrial fibrillation. Eur Heart J Cardiovasc Pharmacother. December 2019. https://doi.org/10.1093/ ehjcvp/pvz073

68 Hanon O, Jeandel C, Jouanny P, et al. Anticoagulant treatment in elderly patients with atrial fibrillation: position paper. Geriatr Psychol Neuropsychiatr Vieil 2019;17:341-55. https://doi.org/10.1684/pnv.2019.0834

69 Konstantinides SV, Meyer G, Becattini C, et al. 2019 ESC Guidelines for the diagnosis and management of acute pulmonary embolism developed in collaboration with the European Respiratory Society (ERS). Eur Heart J 2020;41:543603. https://doi.org/10.1093/eurheartj/ehz405 
70 Kearon C, Akl EA, Ornelas J, et al. Antithrombotic therapy for VTE disease: CHEST Guideline and Expert Panel Report. Chest 2016;149:315-52. https://doi.org/10.1016/j. chest.2015.11.026

71 Geldhof V, Vandenbriele C, Verhamme P, et al. Venous thromboembolism in the elderly: efficacy and safety of non-VKA oral anticoagulants. Thromb J 2014;12:21. https://doi.org/10.1186/1477-9560-12-21

72 Sadlon AH, Tsakiris DA. Direct oral anticoagulants in the elderly: systematic review and meta-analysis of evidence, current and future directions. Swiss Med Wkly 2016;146:w14356. https://doi.org/10.4414/smw.2016.14356

73 Agnelli G, Buller HR, Cohen A, et al. Apixaban for extended treatment of venous thromboembolism. N Engl J Med 2013;368:699-708. https://doi.org/10.1056/NEJMoa1207541

74 Schulman S, Kakkar AK, Goldhaber SZ, et al. Treatment of acute venous thromboembolism with dabigatran or warfarin and pooled analysis. Circulation 2014;129:764-72. https://doi.org/10.1161/CIRCULATIONAHA.113.004450

75 Vanassche T, Verhamme $P$, Wells PS, et al. Impact of age, comorbidity, and polypharmacy on the efficacy and safety of edoxaban for the treatment of venous thromboembolism: an analysis of the randomized, double-blind Hokusai-VTE trial. Thromb Res 2018;162:7-14. https:// doi.org/10.1016/j.thromres.2017.12.005

76 Prins $\mathrm{MH}$, Lensing AW, Bauersachs R, et al. Oral rivaroxaban versus standard therapy for the treatment of symptomatic venous thromboembolism: a pooled analysis of the EINSTEIN-DVT and PE randomized studies. Thromb J 2013;11:21. https://doi.org/10.1186/1477-9560-11-21

77 Deitelzweig S, Keshishian A, Li X, et al. Comparisons between oral anticoagulants among older nonvalvular atrial fibrillation patients. J Am Geriatr Soc 2019;67:1662-71. https://doi.org/10.1111/jgs.15956

78 Eikelboom JW, Wallentin L, Connolly SJ, et al. Risk of bleeding with 2 doses of dabigatran compared with warfarin in older and younger patients with atrial fibrillation: an analysis of the randomized evaluation of longterm anticoagulant therapy (RE-LY) trial. Circulation 2011;123:2363-72. https://doi.org/10.1161/CIRCULATIONAHA. 110.004747

79 Patel MR, Mahaffey KW, Garg J, et al. Rivaroxaban versus warfarin in nonvalvular atrial fibrillation. $N$ Engl J Med 2011;365:883-91. https://doi.org/10.1056/NEJMoa1009638

80 Heidbuchel $\mathrm{H}$, Verhamme P, Alings M, et al. Updated European Heart Rhythm Association Practical Guide on the use of non-vitamin $\mathrm{K}$ antagonist anticoagulants in patients with non-valvular atrial fibrillation. Europace 2015;17:1467507. https://doi.org/10.1093/europace/euv309

81 Kirchhof P, Benussi S, Kotecha D, et al. 2016 ESC Guidelines for the management of atrial fibrillation developed in collaboration with EACTS. Eur Heart J 2016;37:2893-62. https://doi.org/10.1093/eurheartj/ehw210

82 Weber J, Olyaei A, Shatzel J. The efficacy and safety of direct oral anticoagulants in patients with chronic renal insufficiency: a review of the literature. Eur $\mathrm{J}$ Haematol 2019;102:312-8. https://doi.org/10.1111/ejh.13208

83 Park CS, Choi E-K, Kim HM, et al. Increased risk of major bleeding in underweight patients with atrial fibrillation who were prescribed non-vitamin $\mathrm{K}$ antagonist oral anticoagulants. Heart Rhythm 2017;14:501-7. https://doi. org/10.1016/j.hrthm.2016.12.036

84 Lee S-R, Choi E-K, Park CS, et al. Direct oral anticoagulants in patients with nonvalvular atrial fibrillation and low body weight. J Am Coll Cardiol 2019;73:919-31. https://doi.org/10.1016/j.jacc.2018.11.051

85 Chang S-H, Chou I-J, Yeh Y-H, et al. Association between use of non-vitamin $\mathrm{K}$ oral anticoagulants with and without concurrent medications and risk of major bleeding in nonvalvular atrial fibrillation. JAMA 2017;318:1250-9. https:// doi.org/10.1001/jama.2017.13883

86 Bethishou L, Gregorian T, Won K, et al. Management of venous thromboembolism in the elderly: a review of the nonvitamin Koral anticoagulants. Consult Pharm 2018;33:24861. https://doi.org/10.4140/TCP.n.2018.248.

87 Di Nisio M, Porreca E. Prevention of venous thromboembolism in hospitalized acutely ill medical patients: focus on the clinical utility of (low-dose) fondaparinux. Drug Des Devel Ther 2013;7:973-80. https://doi.org/10.2147/DDDT. S38042

88 Alikhan R, Cohen AT, Combe S, et al. Risk factors for venous thromboembolism in hospitalized patients with acute medical illness: analysis of the MEDENOX study. Arch Intern Med 2004;164:963-8. https://doi.org/10.1001/ archinte.164.9.963

89 Lacut K, Le Gal G, Mottier D. Primary prevention of venous thromboembolism in elderly medical patients. Clin Interv Aging 2008;3:399-411. https://doi.org/10.2147/cia.s832

90 Hemon F, Fouchard F, Tromeur C, et al. Association between hospitalization for acute medical illness and VTE risk: a lower efficacy of thromboprophylaxis in elderly patients? Results from the EDITH case-control study. Eur J Intern Med 2017;44:39-43. https://doi.org/10.1016/j. ejim.2017.05.029

91 Depietri L, Marietta M, Scarlini S, et al. Clinical impact of application of risk assessment models (Padua Prediction Score and Improve Bleeding Score) on venous thromboembolism, major hemorrhage and health expenditure associated with pharmacologic VTE prophylaxis: a "real life" prospective and retrospective observational study on patients hospitalized in a Single Internal Medicine Unit (the STIME study). Intern Emerg Med 2018;13:527-34. https:// doi.org/10.1007/s11739-018-1808-z

92 La Regina M, Orlandini F, Marchini F, et al. Combined assessment of thrombotic and haemorrhagic risk in acute medical patients. Thromb Haemost 2016;115:392-8. https://doi.org/10.1160/TH14-12-1050

93 Arpaia GG, Caleffi A, Marano G, et al. Padua prediction score and IMPROVE score do predict in-hospital mortality in Internal Medicine patients. Intern Emerg Med;Jan 2020. https://doi.org/10.1007/s11739-019-02264-4 